\title{
The Impact of Stock Prices on Consumption and Interest Rate in Turkey: Evidence from a Time Varying Vector Autoregressive Model
}

\author{
Ph.D. Candidate Evrim Toren (Eastern Mediterranean University, Cyprus)
}

\begin{abstract}
This paper aims to examine the spillovers from stock prices onto consumption and interest rate for Turkey by using a time-varying vector autoregressive model with stochastic volatility. A three-variable time-varying vector autoregressive model is estimated to capture the time-varying nature of the macroeconomic dynamics in the Turkish economy between real consumption, nominal interest rate and real stock prices. In order to obtain the macroeconomic dynamics in a small open economy, the data covers the period 1987:Q1 until 2013:Q3 in Turkey. The sample data is gathered from the official website of Central Bank of the Republic of Turkey. Overall, this study provides the evidence of significant time-varying spillovers on consumption and interest rate coming from the stock market during financial crises and implications of monetary policy in Turkey. In addition, a timevarying vector autoregressive model with stochastic volatility offers remarkable results about the impact of price shock on consumption levels in Turkey.
\end{abstract}

\section{Introduction}

The relationship between an increase in wealth, whether from real stock (asset) price, real estate or other financial assets and consumption can be explained by the permanent income hypothesis (Friedman, 1957). According to the permanent income hypothesis, real stock (asset) price inflation leads to an increase in the expected lifetime wealth of households and their consumption (Friedman, 1957). In this respect, there is a review of literature regarding the wide international evidence about the major spillovers from the stock market to consumption not only in advanced economies but also in emerging economies. For example, Lettau and Ludvingson (2001) claim that there is an inevitable role of fluctuations in the consumption-wealth ratio for estimating stock returns in the U.S. They find out that the fluctuations in the consumption wealth ratio are very effective, while predicting real stock returns and excess returns on a Treasury bill rate.

As Apergis and Miller (2004) argue, the stock market wealth asymmetrically affects real per capita consumption in the United States. Additionally, Fratzscher and Straub (2010) examine the relationship between asset prices and current account positions for 42 industrialized and emerging market countries. In their study, they model asset price shocks as news shocks about the future productivity. They conclude that the channels via wealth effects and the real exchange rate are very important when the heterogeneity exists in the transmission.

Consistent with these studies, Koivu (2012) analyzes the dynamics between monetary policy, asset prices and consumption in China. Koivu (2012) contends that a loosening of Chna's monetary policy results in higher stock (asset) prices. In addition, a positive shock to residential prices leads to an increase in household consumption when the role of stock prices are very small in China. Using the quarterly, seasonally adjusted data for the euroarea, Sousa (2010) also shows the impact of wealth on consumption. For Sousa (2010), the estimates suggest that wealth effects are particular for currency and deposits, shares and mutual funds. Thus, consumption reacts quickly and positively to the financial liabilities and mortgage loans in the euro area.

When Turkey is concerned, there is are limited studies, which focus on the dynamics in the stock market and the effects on consumption. Binay and Salman (2008) examine the wealth effects on total consumption when the real estate increases by a percent. According to the research findings, Binay and Salman (2008) conclude that a percent change in stock market indexes lead to an increase in consumption in durables. Aydede (2007) investigates the effects of unfunded social security system on consumption for Turkey by using Engle-Granger methodology. In addition, there are also two papers that look at the behavior of the growth performance of Turkish economy by Ulengin and Yentürk (2001) and Çimenoğlu and Yentürk (2005). Both papers use vector autoregression (VAR) models to show how the private consumption is linked to the short-term capital inflows in the stock market of Turkey.

In light of the articulations above, the objective of this paper is to analyze the impact of stock prices on consumption and interest rate in Turkey. Throughout the paper, the methodology does not rely on constant parameter models, as stated in the literature. Time-varying parameter vector auto regressives (TVP-VARs) are very useful for the analysis of macroeconomic issues and offer the time-varying nature of the underlying structure in the economy (Nakajima, 2011). In this view, a TVP-VAR model with stochastic volatility is used in this study. This paper aims to investigate not only the time-varying spillover effect of stock price shocks on consumption and interest setting behavior, but also the general relationship between the variables in a small-open economy. 
The major structural changes and shifts in the Turkish economy over the period of the analysis make Turkey as a country of investigation in this paper. Thus, this study is the fist, which aims to analyze the spillover effect of real stock prices on real consumption and nominal interest rate by using the TVP-VAR model in Turkey. The remainder of the paper is organized as follows: Section 2 introduces the methodology of the TVP-VAR technique. Section 3 specifies the data that is used. Section 4 is devoted to the presentation of the results of a stock price shock on consumption and interest rate. Finally, section 5 summarizes the basic findings and insights of the paper.

\section{Methodology}

Quantifying and analyzing macroeconomic fluctuations has been one of the most important subjects in the economic literature. The pioneer article "Macroeconomics and Reality" by Sims (1980) introduces a vector autoregression (VAR) for the investigation of macroeconomic fluctuations. Sims (1980) contends that the parameters in the VAR specification act according to a first order random walk process, hence the VAR constitutes both temporary and permanent changes to the parameters. In this study, a TVP-VAR model with stochastic volatility proposed by Primiceri (2005) is applied.

According to Nakajima (2011), the TVP-VAR model with stochastic volatility provides possible changes while examining structure of the economy in a flexible and robust manner. The existence of stochastic volatility is very important in this paper because the TVP-VAR model with stochastic volatility prevents the results from having misspecifation, hence the model is estimated by using Markov Chain Monte Carlo (MCMC) methods. The existence of a Bayesian inference enables the model to estimate the TVP-VAR models via MCMC methods in this study. The objective of MCMC methods is to evaluate the joint posterior distributions of the parameters of interest (Nakajima, 2011).

The estimation of a time-varying parameter VAR model with stochastic volatility of the form can be expressed by following Nakajima (2011):

$$
y_{t}=c_{t}+B_{1 t} y_{t-1} B_{s t} y_{t-s}+e_{t}, e_{t} \sim N\left(0, \Omega_{t}\right),(1)
$$

For $\mathrm{t}=\mathrm{s}+1, \ldots, \mathrm{n}$, where $y_{t}$ is a $(\mathrm{kX} 1)$ vector of observed variables, $B_{1 t}, \ldots \ldots B_{s t}$ are $(k X k)$ matrices of time varying coefficients, and ${ }_{t}$ is a $(\mathrm{kXk})$ matrices of time-varying covariance matrix. Thus, the time varying parameters follow a random walk process in this study.

\section{Data}

The study examines the data, which covers the quarterly period of 1987:Q1 until 2013:Q3 in Turkey. This study estimates a three variable TVP-VAR model in order to assess the time varying nature of the macroeconomic dynamics in the Turkish economy by using real consumption, nominal interest rate and real stock prices. The sample data is gathered from the official website of Central Bank of the Republic of Turkey.

The standard unit root tests, namely, Augmented Dickey Fuller (1981) (ADF), Phillips Perron (1988) (PP), Dickey fuller with generalized least squares detrending (DF-GLS), the Kwiatkowski, Phillips, Schmidt and Shin (1992) (KPSS), the Elliot, Rotherberg and Stock (ERS) (1996) point optimal test, the Ng-Perron (2001) modified versions of the PP (NP-MZt) test and the ERS point optimal (NP-MPt) test are followed in this study.

The variables such as real consumption and real stock prices are found to be non-stationary. Thus, these variables are converted to their corresponding growth rates and named as DRSP and DRC. The nominal interest rate is also found to be stationary by using ADF, DF-GLS, ERS, NP-MZt and NP-MPt tests and specified as $D R$.

The stable TVP-VAR is estimated based on four lags by using all the popular lag-length tests, namely the sequential modified LR test statistic, the Akaike information Criterion and the Schwarz information criterion.

\section{Results}

The posterior estimates are computed by drawing $M=10000$ samples. Table. 1 illustrates the estimates for the posterior means, standard deviations, 95\% credible intervals, the convergence diagnostics (CD) of Geweke (1992) and the inefficiency factors of parameters of TVP-VAR model.

The CD statistics confirm that the null hypothesis of the convergence to the posterior distribution is not rejected at the 5 percent level of significance. When the efficiency factors are taken into consideration, Table. 1 shows that the efficiency factors are not so high in general. Since the 95 percent confidence intervals include the estimated posterior mean for every parameters in the TVP-VAR model, the MCMC algorithm provides posterior draws efficiently. 


\begin{tabular}{|c|c|c|c|c|c|c|}
\hline Parameter & Mean & Std. Dev. & $95 \% \mathrm{U}$ & $95 \% \mathrm{~L}$ & $\mathrm{CD}$ & Inefficiency \\
\hline $\mathrm{sb} 1$ & 0.1258 & 0.0638 & 0.0545 & 0.3002 & 0.959 & 158.98 \\
\hline $\mathrm{sb} 2$ & 0.0809 & 0.0431 & 0.0247 & 0.1924 & 0.177 & 129.10 \\
\hline $\mathrm{sa} 1$ & 0.0056 & 0.0015 & 0.0035 & 0.0092 & 0.950 & 46.28 \\
\hline $\mathrm{sa} 2$ & 0.0056 & 0.0015 & 0.0035 & 0.0095 & 0.000 & 20.24 \\
\hline $\mathrm{sh} 1$ & 0.0054 & 0.0014 & 0.0033 & 0.0087 & 0.981 & 30.77 \\
\hline $\mathrm{sh} 2$ & 0.0059 & 0.0017 & 0.0036 & 0.0101 & 0.012 & 37.06 \\
\hline
\end{tabular}

Table 1. Estimation Results of select parameters in the TVP-VAR model

Figure.1 presents the data of the three variables, which are nominal interest rate, real stock prices and real consumption ( $D R, D R S P, D R C)$ in the top panel. The bottom panel is belonging to the corresponding posterior estimates of stochastic volatility. The nominal interest rates are found to exhibit the most stochastic volatility because Turkey has economic crises since the 1990s. Domestic and international macroeconomic instabilities result in four major crises between 1990 and 2011. According to the results, stochastic volatility of consumption growth in Turkey has started to be highly volatile in the middle of the sample period and peaks around in 2001. In addition, stochastic volatility of consumption is also highly volatile in 1994 and 2007 because of the financial crisis and global crisis, respectively. The stochastic volatility of consumption is low and stable both for the early period of the sample until 1994 and for the period between 2001 and 2008. The low stochastic volatility can be regarded as certainty in consumption period, due to the economic and political environment in Turkey. The real stock returns are highly volatile during the early period of sample. Due to the decline in stock returns, the most stochastic volatility replace in 1994.
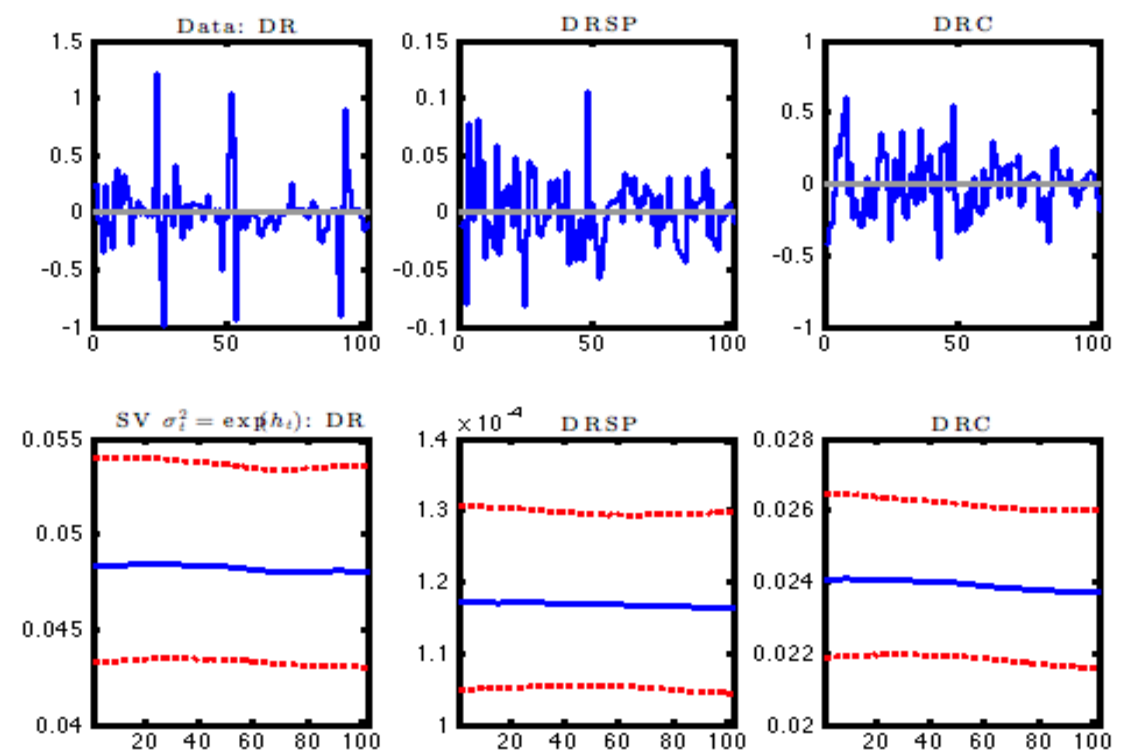

Figure 1. Posterior Estimates for Stockhastic Volatility in the TVP-VAR model

There are different ways to simulate the impulse responses in the TVP-VAR model. In this study, the impulse responses are computed by not only fixing initial shock size equal to the time series average of stochastic volatility over the sample period, but also by using the simultaneous relations at each point for the comparability of the model (Nakajima, 2011). Figure.2 presents the time varying responses at different horizons of one quarter ahead at each point of the sample for the three variables following a shock to real stock price. In this figure, the mean of the posterior is reported together with $16^{\text {th }}$ and $84^{\text {th }}$ percentiles. When there is a shock to real stock price, the impact on stock price itself is generally positive. The effect is not always significant for the one-quarter ahead horizon. However, a positive shock to real stock price affects consumption positively. The effect on consumption is significant at one-quarter ahead horizon for the entire period. When the nominal interest rate is taken into consideration, the behavior of the interest rate that follows a real stock price increase is very interesting. For the one-quarter ahead impulse responses the effect is positive, but the effect is insignificant especially in the 2001 crisis. In addition, in Figure.2, when there is a shock to nominal interest rate, the impact on interest rate itself is positive.

As is seen in Figure.3, if there is a shock to real stock price, the effect on stock price itself is negative in general but a positive shock to real stock price has a positive impact on nominal interest rate. On the other hand, when consumption is concerned, for the four-quarters ahead, the impulse responses are initially negative, and then become positive especially for the period around 1993, 2000 and 2008. 

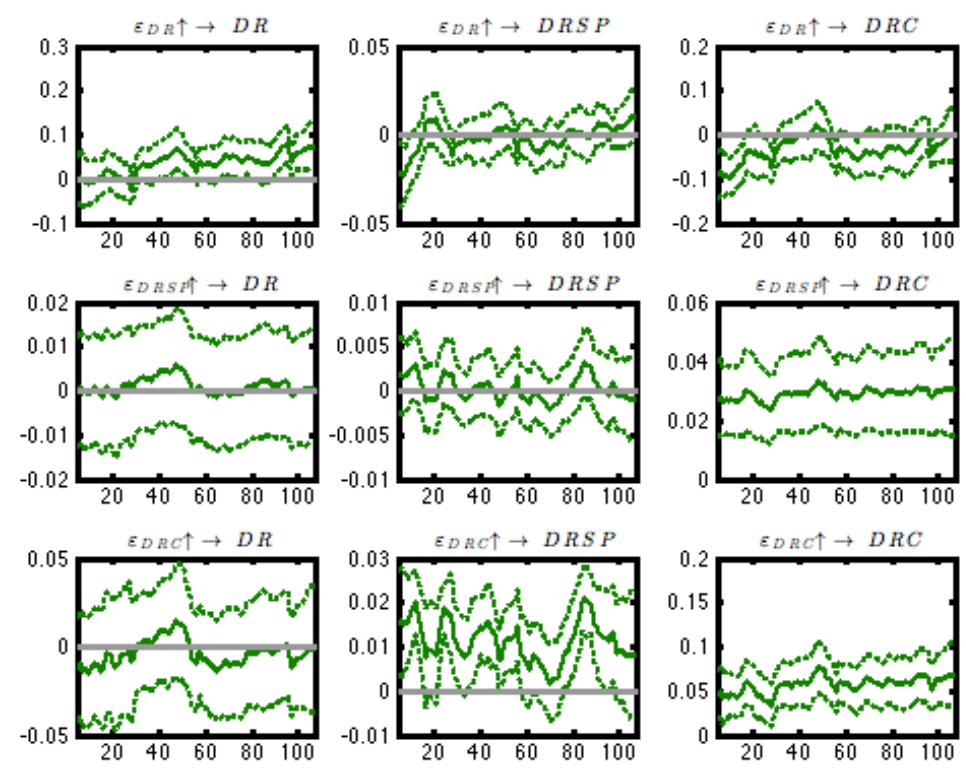

Figure 2. Impulse Responses of the TVP-VAR model following a real stock price shock, 1 -step ahead
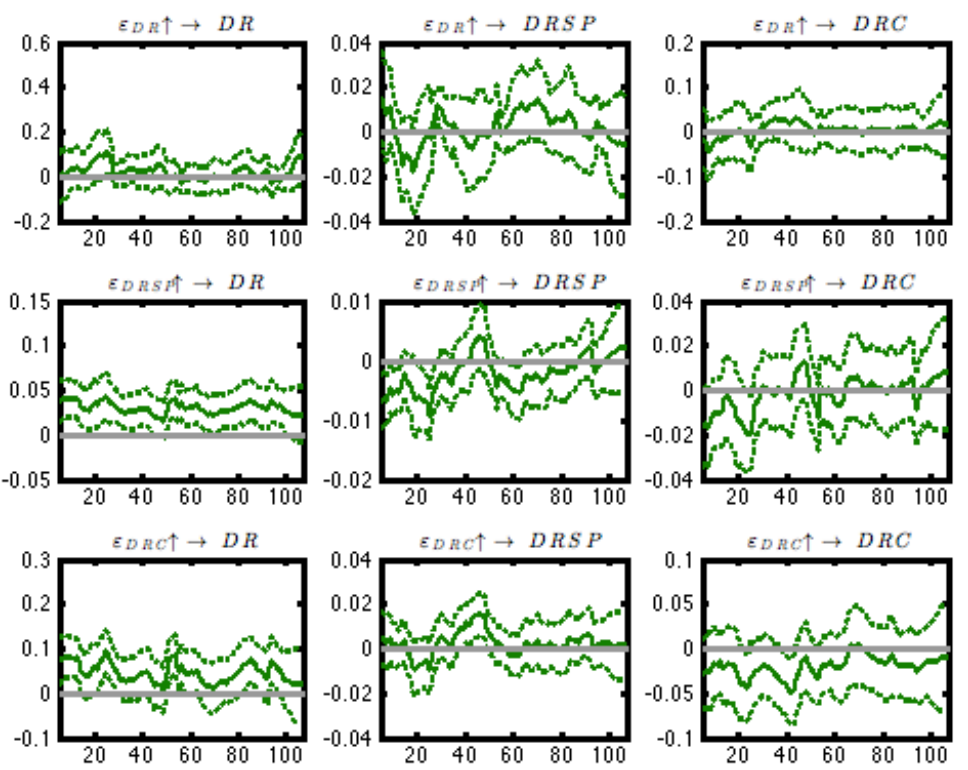

Figure 3. Impulse Responses of the TVP-VAR model following a real stock price shock, 4-steps ahead

Figure.4 displays the impulse responses at 8-steps ahead. If there is a shock to real stock price itself, the effect on stock price itself is generally positive but the effect is not again significant. In addition, a positive shock to real stock price has interesting effects both on consumption and interest rate. As is seen in Figure 8, although the impulse responses are positive in general, the significant responses are observed after the effect weakened during the turbulence in the economy.

In Figure.5, the impulse responses depict a dissimilar pattern to the 12-quarters ahead horizon because the effects are not bigger at longer horizons. When the time varying response trajectories for the three variables are considered, the positive shock to real stock price have the significant effect on consumption and interest rate.

Figure.6 presents the impulse responses of the model at 1994:Q1. For Rodrik (2012), a misguided attempt to keep interest rate low resulted in a sudden capital outflow in Turkey in this year. Before the crisis hit the economy, a general picture of the Turkish economy was based on the poor fiscal stance, high current account deficit, the overvaluation of Lira, the illiquidity of the government according to international standards and the weak banking sector (Ozatay, 2000). For Ozatay (2000), the crisis was unexpected because of the stable foreign exchange reserve levels and interest differentials in the in the period before the crisis. In light of these statements, the impulse responses belonging to 1994 in Figure.6 confirm that when there is a shock to real stock price, the effect on stock price itself is negative and then becomes positive. Following a positive shock to real stock price also leads to firstly a decrease in consumption and then in increase in consumption. However, the interest rate, which follows a real stock price shock, depicts the positive effect in general. 

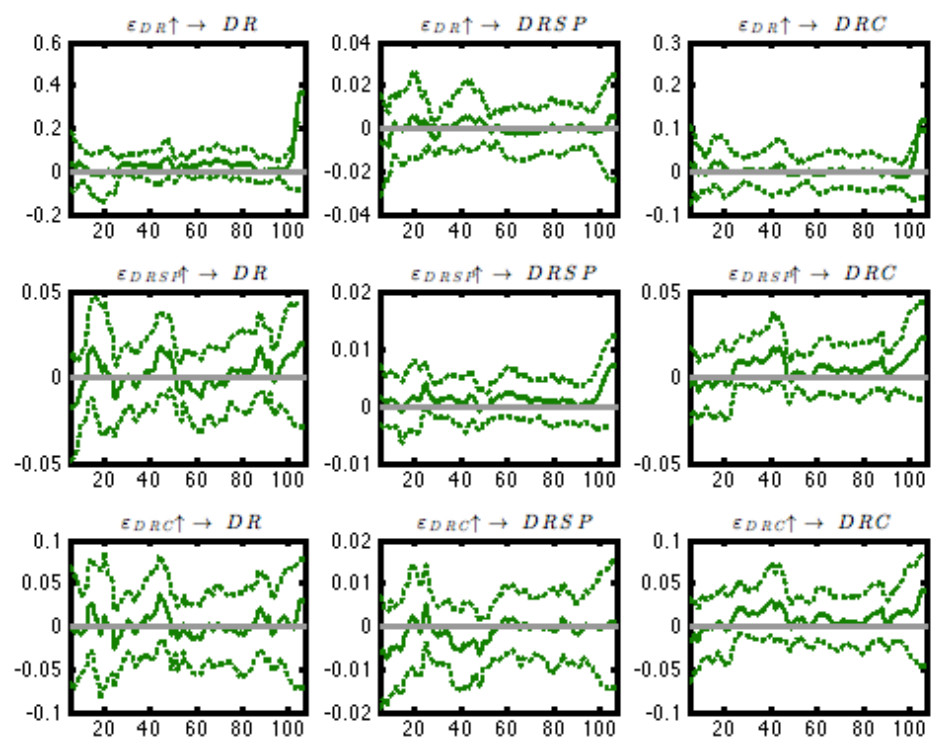

Figure 4. Impulse Responses of the TVP-VAR model following a real stock price shock, 8-steps ahead
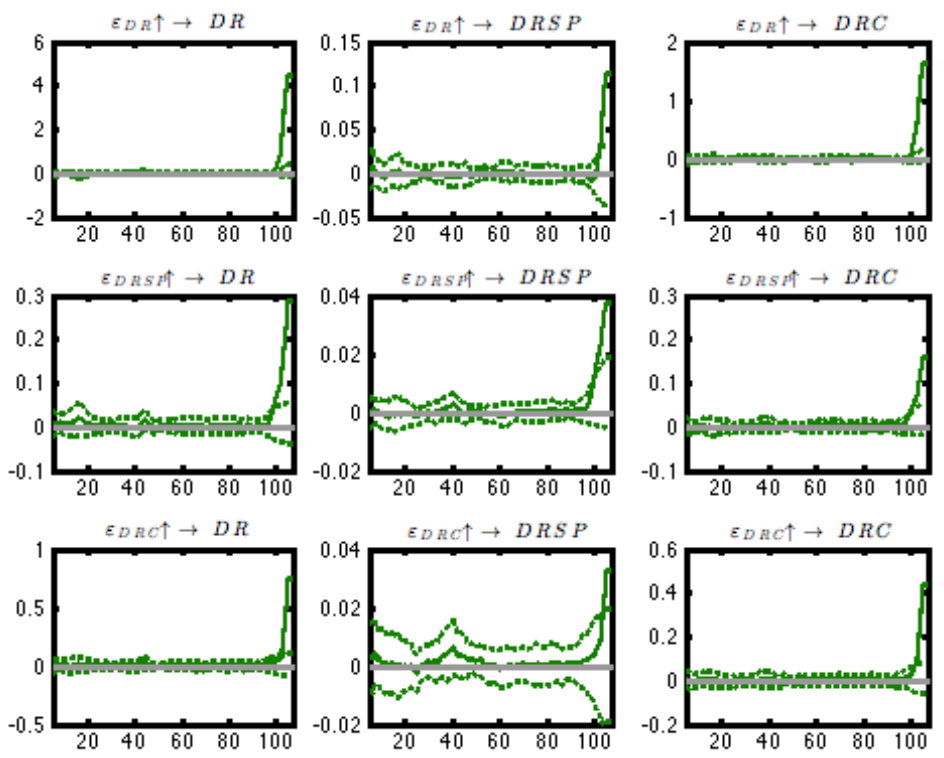

Figure 5. Impulse Responses of the TVP-VAR model following a real stock price shock, 12-steps ahead
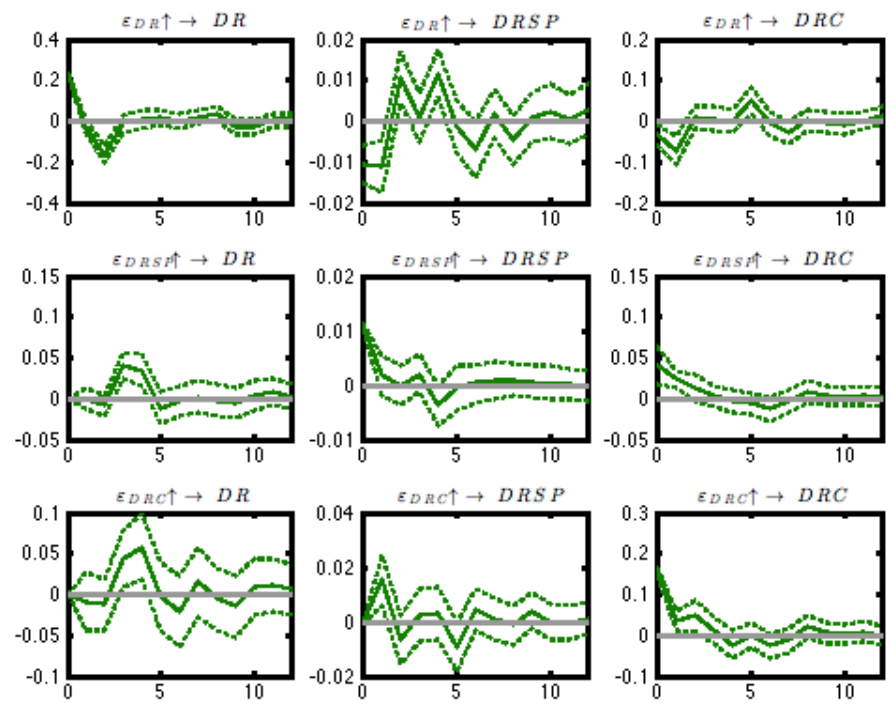

Figure 6. Impulse Responses of the TVP-VAR model at 1994:Q1 
Figure.7 illustrates impulse responses of the TVP-VAR model at 2000:Q4 because there has been another destructive financial crisis, which is more severe than the crisis in 1994. The Turkish economy was in a severe political and financial crisis on February 19, 2001. Ozatay and Sak (2003) contend that the public sector borrowing requirement, ratio of public debt to GNP, current account deficit, inflation level and the ratio of the liabilities of the financial sector were very high in the last quarter of 2000. Thus, in Figure.7, when there is a shock to real stock price, the impact on stock price itself is generally positive. The effect is also significant for the entire year. A positive shock to real stock price affects consumption positively. Thus, the effect on consumption is significant at 2000:Q1. If the nominal interest rate is concerned, the impulse responses are initially negative and then become positive.
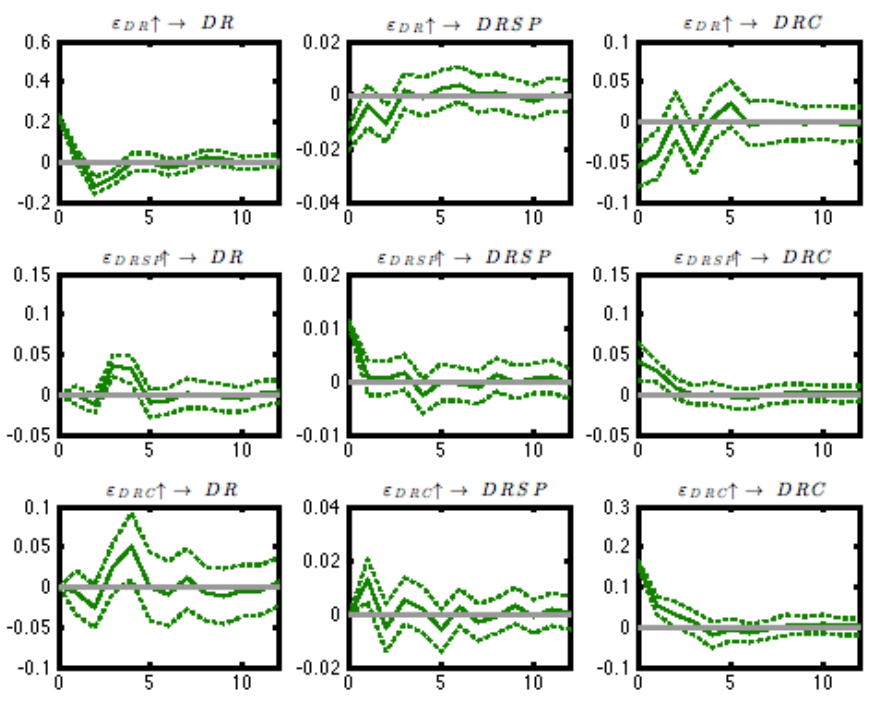

Figure 7. Impulse Responses of the TVP-VAR model at 2000:Q4

Figure. 8 provides impulse responses of the TVP-VAR model in 2007 because there was a great disturbance in the United States' financial markets in this year. According to Krugman (2009), the financial troubles, which lead to the crisis in the financial markets in the U.S. in 2007 consequently created a full-fledged global crisis in 2008. This crisis developed gradually and evolved into a global crisis that significantly hit the Turkish economy (Yendi and Çetin, 2012). In this view, Figure. 8 presents the impulse responses for the three variables of the concern following positive shocks. As is seen, when there is a shock to real stock price, the impact of a real stock price shock on consumption is positive in general. When there is a shock to real stock price, the impact on stock price itself is also positive, too. However, the impulse responses for the interest rate are initially positive, and then become negative.
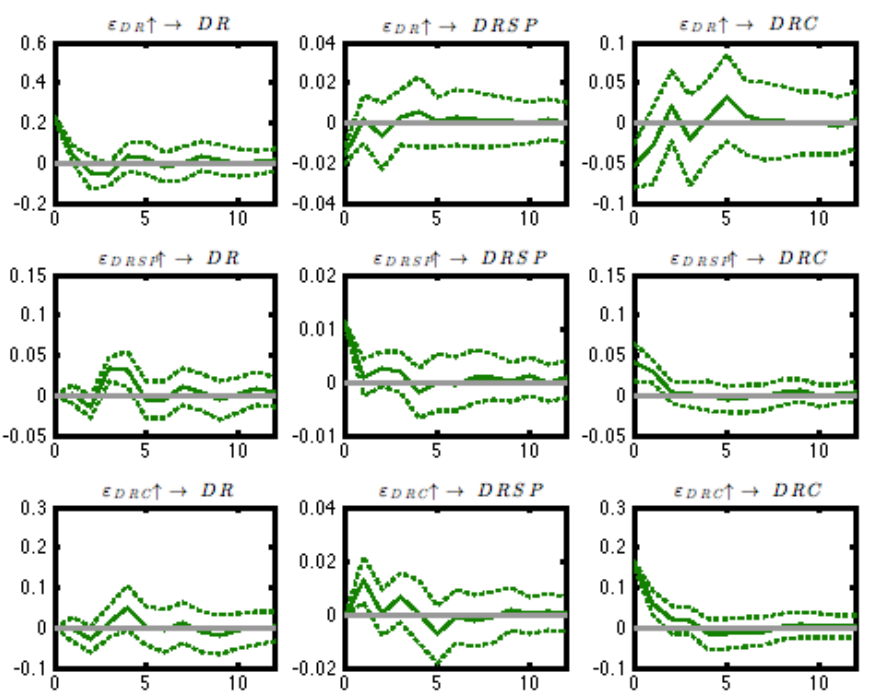

Figure 8. Impulse Responses of the TVP-VAR model at 2007:Q1

Due to the adverse effect of the United States' debt-ceiling crisis of 2011 on the Turkish economy, Figure.9 shows impulse responses of the TVP-VAR model at 2011:Q1. As is seen, a shock to real stock price influences consumption positively because the effect is significant. When there is a shock to real stock price, the impulse 
responses are initially positive and then become negative. The effect is not always significant in 2011. However, when the nominal interest rate is taken into consideration, a positive shock to real stock price affects interest rate positively.
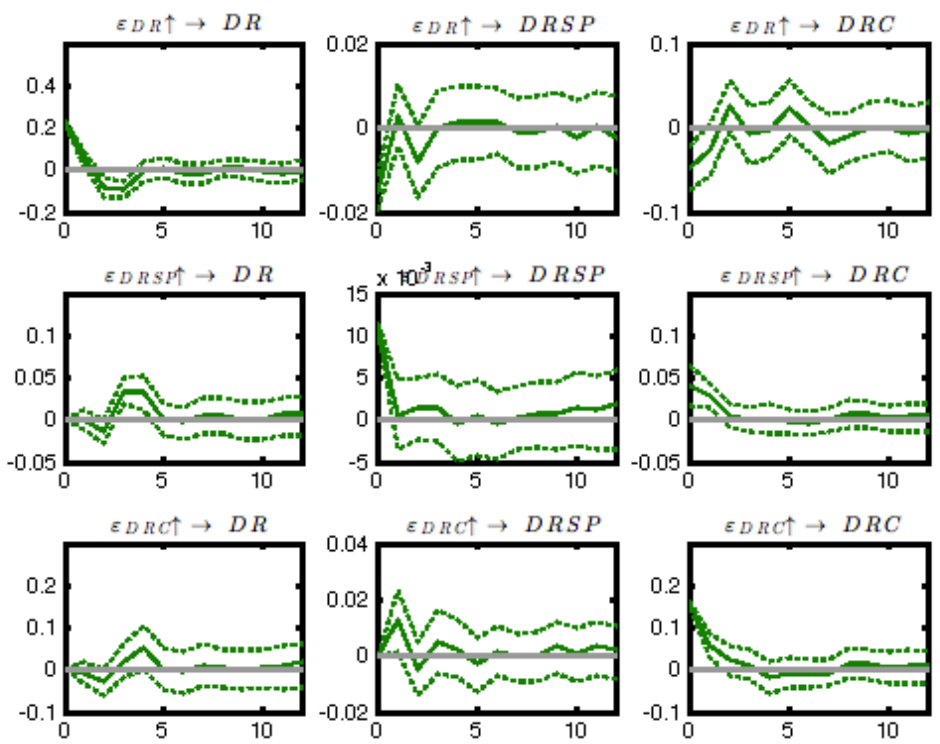

Figure 9. Impulse Responses of the TVP-VAR model at 2011:Q1

\section{Conclusion}

In this study, a three variable TVP-VAR model with stochastic volatility is used to show the impact of real stock prices on real consumption and nominal interest rate for Turkey. The sample data covers the quarterly period of 1987:Q1 - 2013:Q3. The study provides the evidence of significant time-varying spillovers on consumption and interest rate coming from the stock market during financial crises and implications of monetary policy in Turkey. According to the research findings, the results confirm that the real stock price shocks affect consumption positively in Turkey with large and significant effects especially at the one step ahead horizon. Additionally, the periods such as 1994, 2000, 2007 and 2011 are examined to evaluate the relationships between variables in the economic crises. In order to capture the variability in the behavior of both consumption and interest rates, this paper suggests the usage of time-varying model with stochastic volatility.

\section{References}

- $\quad$ Aydede, Yiğit, 2007, “Aggregate Consumption Function and Public Social Security: The First Time Series Study for a Developing Country, Turkey," Applied Economics, p. 1-20.

- Apergis, N. and Miller, S.M. 2004. "Consumption asymmetry and the stock market: further evidence" University of Connecticut, Department of Economics, Working Paper No. 2004-19.

- Binay, S. and Salman, F. 2008. A Critique of Turkish Real Estate Market," Turkish Economic Association Discussion Paper 2008/8. Available via Internet: http://www.tek.org.tr/dosyalar/critique_6may2008.pdf.

- Cimenoglu, A., Yenturk, N. 2005. Effects of International Capital Inflows on the Turkish Economy, Emerging Markets Finance and Trade, 41(1), 90-109.

- Dickey, D. and Fuller, W. 1981. Likelihood ratio statistics for autoregressive time series with a unit root. Econometrica, 49:1057-1072.

- $\quad$ Elliot, G., Rothenberg, T.J. and Stock, J.H. 1996. Efficient tests for an autoregressive unit root. Econometrica, 64:813-836.

- Fratzscher, M. and Straub, R. 2010. Asset prices, news shocks and the current account. CEPR Discussion Paper No. 8080.

- Friedman, M. 1957. A theory of the consumption function. Princeton University Press, Oxford.

- Geweke, J. 1992. Evaluating the accuracy of sampling-based approaches to the calculation of posterior moments, in Bernado, J.M., Berger, J.O., Dawid, A.P. and Smith, A.F.M. (eds), Bayesian Statistics, 4:169188. New York: Oxford University Press.

- Koivu, T. 2012. Monetary policy, asset prices and consumption in China. Economic Systems, 36: 307-325.

- Krugman, Paul (2009). The Great Recession versus the Great Depression, The Conscience of a Liberal, krugman.blogs.nytimes.com, 20 March. 
- $\quad$ Kwiatkowski, D., Phillips, P., Schmidt, P. and Shin, J. 1992. Testing the null hypothesis of stationarity against the alternative of a unit root. Journal of Econometrics, 54:159-178.

- Lettau, M., and Ludvigson, S.C. 2001. Consumption, aggregate wealth, and expected stock returns. Journal of Finance, 56: 815-849.

- Nakajima, J. 2011. Time Varying Parameter VAR Model with Stochastic Volatility: An Overview of Methodology and Empirical Applications. Monetary and Economic Studies, 2: 107-142.

- $\quad \mathrm{Ng}, \mathrm{S}$. and Perron, P. 2001. Lag length selection and the construction of unit root tests with good size and power. Econometrica, 69:1519-1554.

- Primiceri, G. E., “Time Varying Structural Vector Autoregressions and Monetary Policy,” Review of Economic Studies, 72 (3), 2005, pp. 821-852.

- $\quad$ Phillips, C.B.P., Perron, P. 1988. Testing For a Unit Root in Time Series Regression. Biometrika. 75(2), 33536.

- $\quad$ Rodrik, D. 2009. The Turkish Economy after the Crisis, A Paper prepared for the occasion of the $80^{\text {th }}$ anniversary of the Turkish Economics Association Discussion Papers.

- Ozatay, F. 2000. The 1994 Currency in Turkey. Policy Reform, 3:327-52.

- Ozatay, F, Sak, G. 2003. Banking Sector Fragility and Turkey’s 2000-01 Financial Crisis. The CBRT, Research Department.

- $\quad$ Sims, A.C 1980. Macroeconomics and Reality. Econometrica. 48(1), 1-48.

- Sousa, R.M. 2010. Wealth effects on consumption: evidence from the euro area. Banks and Bank Systems, 5 (2): 78-87.

- Uluengin, B. Yenturk, N. 2001. Impacts of Capital Inflows on Aggregate Spending Categories: The Case of Turkey, Applied Economics, 33 (10), 1321-1328. 